\title{
Age, gender, psychological well-being and the impact of losing the latent and manifest benefits of employment in unemployed people
}

$\begin{array}{ll}\text { Authors: } & \text { Peter A. Creed, Griffith University - Gold Coast } \\ & \text { Tania Watson, Griffith University - Gold Coast }\end{array}$

Contact: Associate Professor Peter A. Creed

School of Applied Psychology

GriffithUniversity - Gold Coast

PMB 50 GCMC

Gold Coast Australia 9726

Telephone: +61755528810

Facsimile: +61 755528291

Email: p.creed@griffith.edu.au 


\title{
Age, gender, psychological well-being and the impact of losing the latent and manifest benefits of employment in unemployed people
}

\begin{abstract}
Three hundred and eighty-six unemployed adults were administered surveys measuring well-being, the latent (social support, activity, collective purpose, time structure, status) and manifest (financial strain) benefits of employment, and neuroticism. Participants were divided into three groups: 142 "young" (18-24.9 years), 125 "middle-aged" (2534.9) and 119 "mature-aged" unemployed (aged 35-55 years). It was hypothesised that age and gender effects would be found for well-being, that these would be associated with differences in access to the latent and manifest benefits of employment, and the manifest and latent benefits would interact in predicting well-being. No gender main effects were found. The young unemployed reported higher well-being, more social support, and higher status than the mature group, and less time structure and higher status than the middle-aged group. No differences were identified between the middle-aged and mature unemployed. Neuroticism was the most important individual predictor of wellbeing for all age groups, but particularly for the mature group. Financial strain was a significant predictor in the young and middle-aged groups, and the social support by financial strain interaction was a significant predictor in the young group. Results are discussed in the context of specific models of unemployment and well-being.
\end{abstract}

Keywords: unemployed, latent benefits, manifest benefits, well-being, social support, activity, collective purpose, time structure, status, neuroticism 
Unemployment remains a serious social problem, in Australia, and internationally. The negative well-being consequences of unemployment have been well documented (for recent reviews see Murphy \& Athanasou, 1999; Winefield, 1995). For example, research comparing unemployed with employed samples has consistently found higher levels of psychological distress (Waters \& Moore, 2002) and depression (Waters \& Moore, 2001), and lower levels of self-esteem (Muller, Hicks \& Winocur, 1993) in the unemployed. The evidence is similar for adults loosely connected to the labour market (e.g., with part-time, casual or intermittent work) in that they also have poorer levels of well-being than the full-time employed (Creed \& Machin, 2002). Poor well-being in the unemployed has also been demonstrated to be largely consequential to unemployment, and not the result of those with poorer health "drifting" into unemployment (Creed, 1999).

There are two main theories that seek to explain the effects of unemployment on wellbeing. These are Jahoda's (1982) latent deprivation model, and Fryer's (1995) agency restriction model. Jahoda argued that paid employment provided both manifest (i.e., to do with income) and latent (i.e., to do with meeting psychological needs) benefits to the individual. When employment was lost, the individual was deprived of an income, but it was the loss of the capacity to meet psychological needs that led to a deterioration in mental health. Jahoda proposed that five main psychological needs go unmet when the individual is unemployed. These are the need for time structure, social contact outside of the immediate family, being part of a collective purpose, being engaged in meaningful activities, and having social status. While non-employment activities (e.g., sport) may provide some access to these benefits, Jahoda argued that only the social institution of work was able to meet all needs, and did so in combination with meeting financial needs. 
Fryer, on the other hand, has argued for a more influential role for financial deprivation to account for the decline in well-being in the unemployed. While acknowledging the importance of the latent benefits, he has argued that unemployment "generally results in psychologically corrosive... poverty" (1995, p. 270), and that it is poverty that severs the individual from a meaningful future and leads to a reduction in psychological health.

Evidence for the influence of the latent and manifest benefits of employment has been demonstrated by researchers examining their effects individually, and in concert. Compared with the employed, unemployed people have been shown to have less structured and purposeful time use (Wanberg, Griffiths, \& Gavin, 1997), lower levels of activity (Waters \& Moore, 2002), to be involved in fewer social activities (Underlid, 1996), to feel less involved in a collective purpose, to report lower status (Creed \& Muller, 2003), and to experience more financial strain (Jackson, 1999). Importantly, associations have also been demonstrated between the latent and manifest benefits and psychological well-being, with reduced access associated with poorer well-being (see Haworth, 1997 for a review).

The moderating roles of age and gender on psychological well-being have been reported in the literature, but neither have been widely examined nor examined at all in the context of testing the latent and manifest benefits' hypotheses. Several studies have found that adolescents who fail to engage in full-time employment after leaving school do not suffer psychological ill-health to the same extent as adults (Broomhall \& Winefield, 1990; see also Winefield, Tiggemann, Winefield \& Goldney, 1993), while at the other end of the age spectrum, it has been argued that mature aged unemployed people are also less negatively affected (Warr \& Jackson, 1984). This has prompted 
Warr, Jackson and Banks (1988) to hypothesise a curvilinear association between age and well-being in unemployed people, with the middle-aged unemployed being the most distressed, and the young and older unemployed to be less distressed. There is some support for a curvilinear relationship. Warr and Jackson (1984) examined British unemployed males between the ages of 16 and 64 years (using age cohorts of 16-19, 20$29,30-39,40-49,50-59$ and 60-64 years) and found that the middle-aged reported more financial strain and poorer psychological well-being. Follow-up studies at nine months (Warr \& Jackson, 1985) and two years (Warr \& Jackson, 1987) found that there was greater psychological deterioration for the men aged between 20-59 than those younger or older. In Australia, Rowley and Feather (1987) compared young unemployed males (15-24 years) with middle-aged unemployed males (30-49 years) and found poorer wellbeing in the older group, but found no differences in financial strain. Broomhall and Winefield (1990) also tested across two groups (15-30 years and 40-62 years) and reported poorer mental health and less life satisfaction in the older group. In Israel, Kulik (2001) tested across three age samples (up to 25, 26-35 and 36-52 years), and while the middle-aged were reported to experience a greater decline in health as a result of their employment, no age related differences were found for well-being or financial strain.

Explanations for this curvilinear relationship can be couched in the context of the latent and manifest benefits. For example, deprivation of the manifest benefits may be more severe on the middle-aged unemployed as they are at a stage in life of high financial demands (e.g., mortgages, children), whereas the younger unemployed generally continue to receive financial support from their parents, and the older unemployed have fewer financial demands, for example, having paid off a house mortgage (Warr, et al.). For the 
latent benefits, status may be differentiated by the younger and older unemployed having other legitimate social roles than being unemployed (such as travel or early retirement, respectively) when compared with the middle-aged unemployed (Winefield et al., 1993). Level and types of activities engaged in by the unemployed have been shown to differ according to age. For example, hobby and entertainment-related activities tend to increase least among the middle-aged unemployed, compared with younger and older groups (Warr, 1984). Lastly, young people see the unemployment status as more stigmatising (Kulik, 2001), and tend to socialise more when they become unemployed, whereas the reverse is true for the middle-aged and older unemployed (Warr).

An important omission in the studies to date has been the failure to test for differential effects of unemployment for men and women on psychological well-being and the latent and manifest benefits of employment. Until recently, research within the unemployment domain has focused primarily on men, who were the primary bread winners. In the past, women were assumed not to be as negatively affected by unemployment as men (Kasl \& Cobb, 1979). They were also less likely to be in the workforce and less likely to be the main family provider (Kaufman \& Fetters, 1980). This is no longer the case. There has been a dramatic increase in the number of single, dual-income and single-parent women entering the full-time workforce in Australia (Australian Bureau of Statistics, 2001). In relation to psychological well-being, researchers most often have found that the experience of unemployment is more distressful for men (e.g., Lahelma, 1992; Muller et al, 1993), although the reverse has also been found (e.g., Warr et al., 1985; Warr \& Payne, 1983), while some studies have found no differences (e.g., Feather \& O'Brien, 1986; Winefield \& Tiggemann, 1985). For example, compared with unemployed women, 
Shamir (1986) found unemployed men to have lower morale and to be more anxious, Muller et al. found men to have less vigour, more distress and to be more tired, and Lahelmo (1992) found men to react more negatively to losing a job.

The evidence in relation to gender differences for the latent and manifest benefits is even more sparse. Early researchers assumed that women were not as deprived of the manifest benefits of employment as males, as their need for work was less imperative because they were buffered by the incomes of their spouses (Kauffman \& Fetters, 1980). With more equal labour market participation of women, and males still earning disproportionately more than females (ABS, 2001), it might be expected that contemporary women would report higher levels of financial strain than men. The evidence for this is mixed. Waters and Moore (2002) found that women reported more financial strain than men, but that financial strain was more associated with well-being for men than women, whereas Creed and Macintyre (2001) found no differences between males and females on financial strain or well-being.

Creed and Macintyre (2001) also found no gender differences on any of the latent benefits of employment. Other studies, however, which have examined the latent benefits individually, have identified differences between males and females. Frydenberg and Lewis (1991), for example, reported that young women generally tended to seek social support more so than young males, while Hammarström and Janlert (1997) demonstrated that social support was more strongly associated with well-being for females rather than males. Women have been shown to seek more intrinsic and social rewards in the activities they undertake (Mi'ari, 1996), whereas males have a more instrumental focus (Deci \& Ryan, 1985). Lastly, women have been shown to have a wider range of salient 
roles than males (Warr \& Parry, 1982), and with unemployment, women resort to other legitimate activities (such as home duties; Underlid, 1996) moreso than men.

The studies testing for the effects of the deprivation of the latent and manifest benefits on well-being have assumed a linear relationship amongst the variables. Despite calls in the literature (e.g., Creed \& Macintyre, 2001), no study has examined the interaction effects among the latent benefits, or more importantly, examined the interaction effects between the latent and manifest benefits of employment. It is possible, for example, that deprivation of the manifest benefits will have a direct effect on psychological well-being, as well as an indirect effect by, for instance, reducing the opportunity to socialise and pursue hobby or sporting activities.

The present study will add to the literature, first, by testing for age and gender differences in relation to the latent and manifest benefits of employment and well-being. Consistent with the curvilinear well-being and unemployment hypothesis, middle-aged unemployed are expected to have poorer well-being than the younger and older unemployed. Consistent with Jahoda's and Fryer's hypotheses, age differences in wellbeing are expected to be associated with differences in access to the latent and manifest benefits of employment. Consistent with gender differences found in the impact of loss of the latent and manifest benefits, age and gender interaction effects are expected for wellbeing. Second, to test the hypothesis that the loss of the manifest benefits operates to affect well-being in a direct fashion, as well as by impacting on the latent benefits, this study will also test for interaction effects between the manifest benefits and all five latent benefits. Numerous studies have demonstrated that personality, especially neuroticism, is a strong and consistent predictor of well-being across a wide range of populations (Creed, 
Machin \& Hicks, 1996; Diener, Suh, Lucas \& Smith, 1999), thus neuroticism will be measured and controlled for in the analyses.

\section{Method}

\section{Participants}

A total of 413 participants were surveyed. Of these, 27 participants were excluded from the analyses because they were too young ( $<18$ years, to avoid school-leavers without paid work experience), too old ( $>55$ years, to avoid participants who may have been more correctly retired or semi-retired), or had not completed all aspects of the survey. This left 386 participants, 215 (56\%) males and 171 (44\%) females, whose mean age was 30.88 years $(S D=10.44)$ and who had been unemployed on average for 16.19 months $(S D=21.70)$. For the purposes of the age comparison analyses, participants were divided into three groups: 142 considered to be "young unemployed" (aged 18-24.9 years, comprising 80 [56\%] males and 62 [44\%] females, with a mean age of 21.17 years $[S D=1.94]$ and average length of unemployment of 8.60 months $[S D=12.20]), 125$ considered "middle-aged unemployed" (aged 25-34.9 years, comprising 67 [54\%] males and 58 [46\%] females, with a mean age of 28.94 years [SD $=2.87]$ and average length of unemployment of 114.80 months $[S D=23.09]$ ), and 119 considered "mature aged unemployed" (aged 35-55 years, comprising 68 [57\%] males and 51 [43\%] females, with a mean age of 44.56 years $[S D=6.02]$ and average length of unemployment of 16.92 months $[S D=24.32])$. These age divisions parallel those utilized by Kulik (2001) and are consistent with the unemployment by age reporting by the Australian Bureau of Statistics (Australian Bureau of Statistics, 2003). 


\section{Measures}

Psychological Distress. The 12-item General Health Questionnaire (GHQ; Goldberg, 1972) has been widely used and recommended for use as a screening device for psychological distress in occupational settings (e.g., Warr, 1987). Respondents were asked to report on how they felt recently on a range of variables, including cognitive processing, self-esteem, anxiety and depression. A sample item was "Have you recently been able to concentrate on whatever you're doing?". Responses were scored on a fourpoint scale ranging from zero to three, using anchors such as "better than usual/same as usual/less than usual/much more than usual". This gave a possible range of $0-36$, with higher scores indicating more psychological distress. The internal reliability coefficient for this sample was .91 .

Latent Benefits of Employment. Five 7-item sub-scales from the Latent and Manifest Benefits scale (LAMB; Muller, Creed, Waters \& Machin, 2000) were used to measure the five latent benefits of time structure, social support, collective purpose, status, and activity. Respondents were asked to indicate the strength of their agreement to bipolar statements, such as "Time usually drags for me/Time rarely drags for me" (time structure), "I regularly do things with other people/I rarely do things with other people" (social support), "I usually feel a part of the community/I rarely feel a part of the community" (collective purpose), "What I do is important/What I do is not important" (status), and "I usually have a lot of things to do/I rarely have a lot of things to do" (activity). This gave a possible range of 7-35 for each sub-scale, with lower scores indicating more access to the latent benefits. The internal reliability coefficients were .88 
(time structure), .94 (social support), .90 (collective purpose), .92 (status) and .90 (activity).

Manifest Benefit of Employment. The 7-item financial strain sub-scale of the LAMB scale (Muller et al., 2000) was used to measure this construct. Respondents were asked to indicate the strength of their agreement to a series of bipolar statements, such as "I can usually live on the money I receive/I usually have trouble living on the money I receive". This gave a possible range of 7-35, with higher scores indicating more financial distress. The internal reliability coefficient for this scale was .94 .

Neuroticism. The 12-item sub-scale from the short version of the Eysenck Personality Questionnaire-Revised (EPQ-R: Eysenck \& Eysenck, 1996) was used to measure neuroticism. Participants were asked to answer "yes" or "no" to questions, such as "Are your feelings easily hurt?" and "Do you often feel lonely?". Responses were scored one for "yes" and two for "no", giving a possible range of 12-24, with higher scores indicating a lower level of neuroticism. The internal reliability coefficient for this sample was .82 .

\section{Procedure}

The study was cross-sectional, and used a convenience sample of anonymous, unemployed volunteers who were surveyed as they utilised the national employment agency in Australia. 


\section{Results}

To test the construct validity of the scales used in the study, all 66 items (General Health Questionnaire $=12$ items; latent benefits of Time Structure $=7$, Social Support $=$ 7, Collective Purpose $=7$, Status $=7$, Activity $=7$; manifest benefits of Financial Strain $=$ 7 ; Neuroticism $=12$ ) were included in a principal axis factor analysis, using an oblique (direct oblimin) rotation. The Kaiser-Meyer-Olkin Measure of Sampling Adequacy (.90) and Bartlett's Test of Sphericity $(p<.001)$ indicated the data were suitable for factor analysis (Tabachnik \& Fidell, 1996). Eight factors were rotated, which reflected the eight scales utilised. This solution was factorially simple and interpretable. There were no cross-loadings, no items with nil loadings, and all items loading on the appropriate latent factors. All factors had eigenvalues greater than one, and the solution accounted for $60 \%$ of the variance.

Summary data for all variables are reported in Tables 1 and 2; correlations among variables are reported in Tables 3 and 4 . In preliminary analyses, the three groups of Young, Middle-aged and Mature unemployed were shown not to differ on proportions of males and females included. The groups did differ on length of unemployment, $F(2,383)$ $=6.07, p=.003$, with the Young group being unemployed for fewer months than the Middle-aged group $(p=.033)$ and the Mature group $(p=.003)$. No difference was found between the Middle-aged and Mature groups. While it is expected that the Young group would be unemployed for fewer months, as they have had less time to accumulate lengthy periods of unemployment, it is also the case that indications of length of unemployment are very unreliable and are influenced by such factors as the previous reference job used, faulty or socially desirable estimations when the unemployment 
period is of a long duration, and the influence of breaks such as holidays or incapacity for work that affect the overall estimation. Because of the differences identified, Length of Unemployment was included in all analyses as a covariate (due to the skewed nature of the distribution of Length of Unemployment, scores for this variable were transformed using a $\log 10$ transformation).

For the Total, Young (Table 3) and Middle-aged (Table 4) samples, GHQ was meaningfully $(\geq .32$, Tabachnik \& Fidell, 1996) correlated with LAMB-CP, LAMB-FS and EPQ-R, such that the more Psychological Distress reported the less access to the Collective Purpose latent benefit, the more Financial Strain and the higher the level of Neuroticism. For the Mature sample (Table 4), GHQ was only meaningfully correlated with Neuroticism, with the more Psychological Distress associated with higher levels of Neuroticism. No meaningful correlations were identified between age, gender and length of unemployment and Psychological Distress, the Latent and Manifest Benefits or Neuroticism in the Total sample or any sub-sample. 
Table 1

Summary data for variables of Psychological Distress, the Latent Benefits of

Employment, Financial Strain and Neuroticism for the three age groups of Young,

Middle and Mature, and the Total sample

\begin{tabular}{|c|c|c|c|c|c|c|c|c|}
\hline \multirow[b]{2}{*}{ Variables } & \multicolumn{2}{|c|}{$\begin{array}{l}\text { Young } \\
(N=142)\end{array}$} & \multicolumn{2}{|c|}{$\begin{array}{l}\text { Middle-aged } \\
\qquad(N=125)\end{array}$} & \multicolumn{2}{|c|}{$\begin{array}{l}\text { Mature } \\
(N=119)\end{array}$} & \multicolumn{2}{|c|}{$\begin{array}{c}\text { Total } \\
(N=386)\end{array}$} \\
\hline & $M$ & $S D$ & $M$ & $S D$ & $M$ & $S D$ & $M$ & $S D$ \\
\hline GHQ & 14.01 & 7.53 & 15.36 & 7.60 & 16.45 & 6.94 & 15.20 & 7.43 \\
\hline LAMB-TS & 30.31 & 9.64 & 27.19 & 10.47 & 28.94 & 11.58 & 28.87 & 10.59 \\
\hline LAMB-SS & 23.81 & 11.60 & 25.73 & 11.40 & 28.82 & 11.42 & 25.97 & 11.63 \\
\hline LAMB-CP & 29.32 & 10.28 & 28.91 & 9.91 & 29.29 & 10.87 & 29.18 & 10.32 \\
\hline LAMB-ST & 16.78 & 8.96 & 20.01 & 9.47 & 20.99 & 10.42 & 19.12 & 9.74 \\
\hline LAMB-AC & 20.49 & 7.94 & 22.14 & 9.23 & 22.85 & 10.01 & 21.76 & 9.07 \\
\hline LAMB-FS & 35.85 & 10.23 & 36.78 & 11.20 & 38.56 & 11.53 & 36.99 & 10.99 \\
\hline EPQ-R & 18.50 & 3.45 & 18.51 & 3.42 & 18.79 & 3.06 & 18.59 & 3.32 \\
\hline
\end{tabular}

Note: $\mathrm{GHQ}=12$-item General Health Questionnaire; LAMB-TS $=7$-item Time Structure sub-scale from the Latent and Manifest Benefit scale; LAMB-SS = 7-item Social Support sub-scale from the LAMB; LAMB-CP $=7$-item Collective Purpose sub-scale from the LAMB scale; LAMB-ST $=7$-item Status subscale from the LAMB; LAMB-AC = 7-item Activity sub-scale from the LAMB; LAMB-FS $=7$-item Financial Strain sub-scale from the LAMB; EPQ-R $=12$-item Neuroticism sub-scale from the Eysenck Personality Questionnaire - Revised. 
Table 2

Summary data for variables of Psychological Distress, the Latent Benefits of Employment, Financial Strain and Neuroticism for Males and Females in the three age groups of Young, Middle and Mature, and the Total sample

\begin{tabular}{|c|c|c|c|c|c|c|c|c|c|c|c|c|c|c|c|c|}
\hline \multirow[b]{4}{*}{ Variables } & \multirow{3}{*}{\multicolumn{2}{|c|}{$\begin{array}{l}\text { Young } \\
\text { Males } \\
(N=80)\end{array}$}} & \multirow{3}{*}{\multicolumn{2}{|c|}{$\begin{array}{l}\text { Young } \\
\text { Females } \\
(N=62)\end{array}$}} & \multirow{3}{*}{\multicolumn{2}{|c|}{$\begin{array}{l}\text { Middle-aged } \\
\qquad \begin{array}{l}\text { Males } \\
(N=67)\end{array}\end{array}$}} & \multirow{3}{*}{\multicolumn{2}{|c|}{$\begin{array}{l}\text { Middle-aged } \\
\text { Females } \\
\qquad(N=58)\end{array}$}} & \multirow{3}{*}{\multicolumn{2}{|c|}{$\begin{array}{l}\text { Mature } \\
\text { Males } \\
(N=68)\end{array}$}} & \multirow{3}{*}{\multicolumn{2}{|c|}{$\begin{array}{l}\text { Mature } \\
\text { Females } \\
(N=51)\end{array}$}} & \multirow{3}{*}{\multicolumn{2}{|c|}{$\begin{array}{l}\text { Total } \\
\text { Males } \\
(N=215)\end{array}$}} & \multirow{3}{*}{\multicolumn{2}{|c|}{$\begin{array}{l}\text { Total } \\
\text { Females } \\
(N=171)\end{array}$}} \\
\hline & & & & & & & & & & & & & & & & \\
\hline & & & & & & & & & & & & & & & & \\
\hline & $M$ & $S D$ & $M$ & $S D$ & $M$ & $S D$ & $M$ & $S D$ & $M$ & $S D$ & $M$ & $S D$ & $M$ & $S D$ & $M$ & $S D$ \\
\hline GHQ & 14.35 & 7.59 & 13.56 & 7.50 & 14.58 & 7.02 & 16.31 & 8.23 & 17.23 & 6.64 & 15.42 & 7.26 & 15.33 & 7.21 & 15.05 & 7.73 \\
\hline LAMB-TS & 30.00 & 9.44 & 30.71 & 9.95 & 26.07 & 9.83 & 28.54 & 11.16 & 28.74 & 11.34 & 29.22 & 12.00 & 28.38 & 10.28 & 29.53 & 10.98 \\
\hline LAMB-SS & 24.43 & 12.22 & 23.03 & 10.79 & 25.15 & 11.34 & 26.51 & 11.58 & 28.79 & 11.07 & 28.84 & 11.98 & 26.03 & 11.70 & 25.93 & 11.61 \\
\hline LAMB-CP & 30.81 & 9.41 & 27.40 & 11.08 & 29.04 & 9.98 & 28.59 & 9.90 & 29.55 & 11.28 & 28.93 & 10.39 & 29.86 & 10.19 & 28.26 & 10.45 \\
\hline LAMB-ST & 16.42 & 8.17 & 17.24 & 9.93 & 19.58 & 8.63 & 20.47 & 10.49 & 21.42 & 10.79 & 20.41 & 9.97 & 18.99 & 9.41 & 19.28 & 10.19 \\
\hline LAMB-AC & 20.01 & 7.45 & 21.11 & 8.54 & 20.34 & 8.50 & 24.36 & 9.65 & 24.30 & 10.00 & 20.92 & 9.79 & 21.47 & 8.82 & 22.16 & 9.39 \\
\hline LAMB-FS & 35.86 & 10.40 & 35.83 & 10.10 & 35.60 & 11.59 & 38.14 & 10.66 & 38.68 & 11.32 & 38.40 & 11.91 & 36.67 & 11.11 & 37.38 & 10.85 \\
\hline EPQ-R & 18.35 & 3.40 & 18.69 & 3.54 & 18.85 & 3.21 & 18.12 & 3.68 & 18.31 & 2.84 & 19.43 & 3.26 & 18.49 & 3.16 & 18.72 & 3.53 \\
\hline
\end{tabular}

Note: See Table 1 for legend 
Table 3

Bivariate correlations among Psychological Distress, the Latent Benefits of Employment,

Financial Strain and Neuroticism for the Total (above diagonal; $N=386$ ) and Young

(below diagonal; $N=142$ ) samples

Variables

12

3

4

5

6

7

8

1. GHQ

$-.04$

$.27 * * *$

$.32 * * *$

$.22 * * * \quad .21 * * * \quad .40 * * *-.57 * * *$

2. LAMB-TS

$-.03$

$-.03$

$\begin{array}{lll}-.10 * & -.12 * & -.07\end{array}$

.01

.00

3. LAMB-SS .28** .04 -

$\begin{array}{llll}.49 * * * & .35 * * * & .22 * * * & .27 * * * \\ -.25 * * *\end{array}$

4. LAMB-CP $.36^{* * *}-.10$

$.47 * * *$

$.30 * * * \quad .31 * * * \quad .35 * * *-.24 * * *$

5. LAMB-ST

$.14 \quad-.14$

$.46^{* * *} .28^{* *}-$

$.63 * * *-.03$

$.20 * * *$

6. LAMB-AC

$.16-.17 *$

$.25 * * \quad .28 * * \quad .60 * * *$

$.03-.19 * * *$

7. LAMB-FS

$$
.45 * * *-.10
$$

$.18^{*}$

$.36^{* * *} \quad .08$

$.18^{*}-$

$-.26^{* * *}$

8. EPQ-R

$-.61 * * * \quad .06$

$\begin{array}{lll}-.35 * * * & -.37 * * * & -.18\end{array}$

$-.26 * *-.35 * * *$

Note 1: $\quad$ See Table 1 for legend

Note 2: $\quad *=p<.05 ; * *=p<.01 ; * * *=p<.001$ 
Table 4

Bivariate correlations among Psychological Distress, the Latent Benefits of Employment,

Financial Strain and Neuroticism for the Middle-aged (above diagonal; $N=125$ ) and

Mature (below diagonal; $N=119$ ) samples

$\begin{array}{lllllllll}\text { Variables } & 1 & 2 & 3 & 4 & 5 & 6 & 7 & 8\end{array}$

1. GHQ $\quad-\quad-.06 \quad .19 * * \quad .35 * * * \quad .24 * * \quad .28 * * \quad .49 * * *-.52 * * *$

$\begin{array}{llllllllll}\text { 2. } \text { LAMB-TS } & -.01 & - & -.06 & -.07 & -.08 & -.03 & .01 & .09\end{array}$

3. LAMB-SS $.30 * *-.05 \quad-\quad .49 * * * \begin{array}{llllll}* & & .32 * * & .24 * * & .18^{*} & -.21 *\end{array}$

4. LAMB-CP $.26^{* *}-.14 \quad .54 * * *-\quad .32 * * * \quad .34 * * * \quad .43^{* * *}-.17$

5. LAMB-ST $\quad .23 * \quad-.09 \quad .20 * \quad .33 * * *-\quad .59 * * * \quad .03 \quad-.27 * *$

$\begin{array}{lllllllll}\text { 6. } & \text { LAMB-AC } & .17 & .00 & .14 & .34 * * * & .67 * * *- & .10 & -.20 *\end{array}$

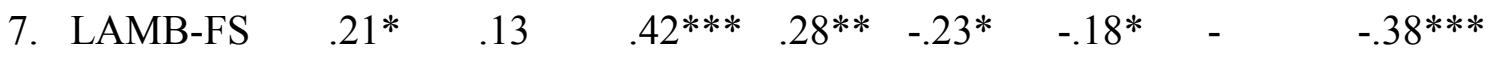

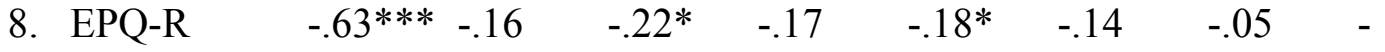

Note 1: $\quad$ See Table 1 for legend

Note $2: \quad *=p<.05 ; * *=p<.01 ; * * *=p<.001$

Age Group and Gender Effects

To test for age and gender effects on Psychological Distress and the Latent and Manifest Benefits of employment, a multivariate analysis of variance (MANOVA) was undertaken. The dependent variables in this analysis were GHQ, Time Structure, Social Support, Collective Purpose, Status, Activity and Financial Strain. The independent 
variables were group (Young, Middle-aged and Mature) and Gender. The analysis was run with and without Neuroticism and Length of Unemployment as covariates. As there were no substantial differences in the results produced by the two analyses, the MANOVA rather than the MANCOVA is reported (Hair, Anderson, Tatham \& Black, 1998). A separate 2 x 3 ANOVA indicated no difference among the three age groups on levels of Neuroticism $(p=.61)$, no differences between males and females $(p=.47)$, and no interaction effect $(p=.10)$. Significant univariate effects are reported for the MANOVA. These were Group main effects for GHQ, $F(2,380)=3.40, p=.034$, Social Support, $F(2,380)=6.25, p=.002$, and Status, $F(2,380)=6.52, p=.002$. A significant Group x Gender effect was identified for Activity, $F(2,380)=5.21, p=.006$. No significant main effects for Gender were identified. For the Group effects, post hoc analyses (Tukey's HSD) indicated that when compared with the Mature unemployed, the Young unemployed reported significantly less Psychological Distress $(p=.021)$, more Social Support $(p=.001)$, and higher Status $(p=.001)$. When compared with the Middleaged unemployed, the Young unemployed reported less Time Structure $(p=.045)$ and higher Status $(p=.018)$. No differences were identified between the Middle-aged and Mature unemployed. For the Group x Gender interaction effect, there were no differences on levels of Activity for Young and Middle-aged unemployed males, who both had significantly higher levels than the Mature unemployed males; whereas there were no differences on Activity for Young and Mature unemployed females, who both had significantly more Activity than the Middle-aged unemployed females (See Figure 1). 


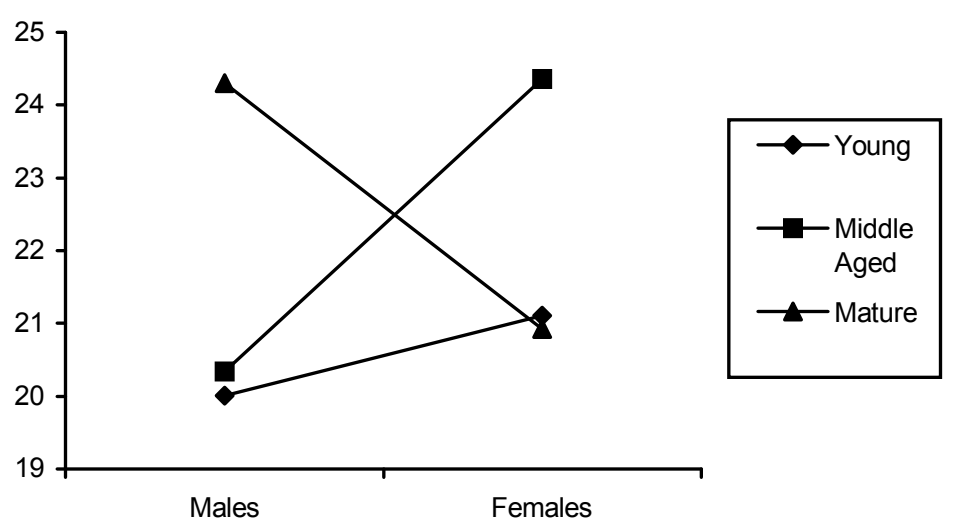

Figure 1: Group x Gender interaction effect for Activity, where higher scores indicate less access to the latent benefit of Activity.

\section{Predicting Psychological Distress}

To test the contribution of the Latent and Manifest Benefits and any interaction effects in predicting Psychological Distress for different age groups, four standard multiple regression analyses were conducted, one for the Total sample, and one for each of the age groups. For all analyses, GHQ was entered as the dependent variable, and Time Structure, Social Support, Collective Purpose, Status, Activity, Financial Strain, the interaction terms for Time Structure x Financial Strain, Social Support x Financial Strain, Collective Purpose x Financial Strain, Status x Financial Strain, Activity x Financial Strain, Neuroticism, Gender, Length of Unemployment and Age were entered as the independent variables. For the regression analysis using the Total sample, an Age Group variable was included instead of the continuous variable of Age. To avoid problems with multicollinearity, the interaction terms were calculated with a centred score approach, using a deviation from the mean transformation (Tabachnik \& Fidell, 1996). Dummy variables were created for Age Group (base level $=$ Young unemployed) and Gender (base level $=$ female). Summary data, including the semi-partial regression coefficients for each predictor variable, are included in Tables 5 and 6. A semi-partial regression 
coefficient is the contribution an individual predictor makes to the dependent variable after the other predictor variables have been statistically controlled.

The results of the first analysis, utilising the Total sample, show that together the variables account for a significant $44.8 \%$ of the variance in Psychological Distress, $F(16$, $369)=18.70, p<.001$. Neuroticism was the most important predictor $(\beta=-.46)$ making a significant unique contribution of $17.72 \%, t(369)=-10.87, p<.001$. Financial Strain was the second most important predictor $(\beta=.26)$ making a significant unique contribution of $4.84 \%, t(369)=5.69, p<.001$. The interaction term Social Support $x$ Financial Strain $(\beta$ $=.10)$ made a significant unique contribution of $.60 \%, t(369)=1.99, p=.047$. Specifically for the interaction effect, high Financial Strain was associated with increased Psychological Distress when Social Support was low (See Figure 2). Lastly, Age Group $(\beta=.12)$ made a significant unique contribution of $1.02 \%, t(369)=2.61, p=.009$, where being in the Mature unemployed group was associated with more Psychological Distress (see Table 5). 
Table 5

Summary data for Standard Multiple Regression Analysis for Variables Predicting

Psychological Distress; $N=386$

\begin{tabular}{lcccc}
\hline Variable & $B$ & $S E B$ & $B$ & Semi-partial \\
\hline LAMB-TS & -0.01 & 0.03 & -0.01 & -0.01 \\
LAMB-AC & 0.04 & 0.05 & 0.05 & 0.04 \\
LAMB-SS & -0.02 & 0.03 & -0.03 & -0.03 \\
LAMB-CP & 0.06 & 0.04 & 0.09 & 0.07 \\
LAMB-ST & 0.06 & 0.04 & 0.08 & 0.05 \\
LAMB-FS & 0.18 & 0.03 & $0.26^{* * *}$ & 0.22 \\
LAMB-TS x LAMB-FS & 0.00 & 0.00 & 0.00 & 0.00 \\
LAMB-AC x LAMB-FS & 0.00 & 0.00 & 0.01 & 0.00 \\
LAMB-SS x LAMB-FS & 0.01 & 0.00 & $0.10^{*}$ & 0.08 \\
LAMB-CP x LAMB-FS & 0.00 & 0.00 & 0.05 & 0.04 \\
LAMB-ST x LAMB-FS & -0.00 & 0.00 & -0.01 & -0.01 \\
EPQ-R & -1.03 & 0.10 & $-0.46^{* * *}$ & -0.42 \\
Gender & 0.12 & 0.59 & 0.01 & 0.01 \\
Group (Middle-aged UE) & 1.10 & 0.71 & 0.07 & 0.06 \\
Group (Mature UE) & 1.98 & 0.76 & $0.12^{* *}$ & 0.10 \\
Length of Unemployment & -0.56 & 0.39 & -0.06 & -0.06 \\
& & & & \\
\hline
\end{tabular}

Note 1: See Table 1 for legend. LAMB-TS x LAMB-FS = interaction term between Time Structure LAMB sub-scale and Financial Strain LAMB sub-scale; LAMB-AC x LAMB-FS = Activity sub-scale interaction term; LAMB-SS $\times$ LAMB-FS = Social Support interaction term; LAMB-CP $\times$ LAMB-FS = Collective Purpose interaction term; LAMB-ST x LAMB-FS = Status interaction term; Group (Middleaged UE) = dummy variable representing Middle-aged unemployed group; Group (Mature UE) = dummy variable indicating Mature unemployed group.

Note 2: $\quad R^{2}=0.45$, Adjusted $R^{2}=0.42$.

Note 3: $*=p<.05 ; * *=p<.01 ; * * *=p<.001$ 


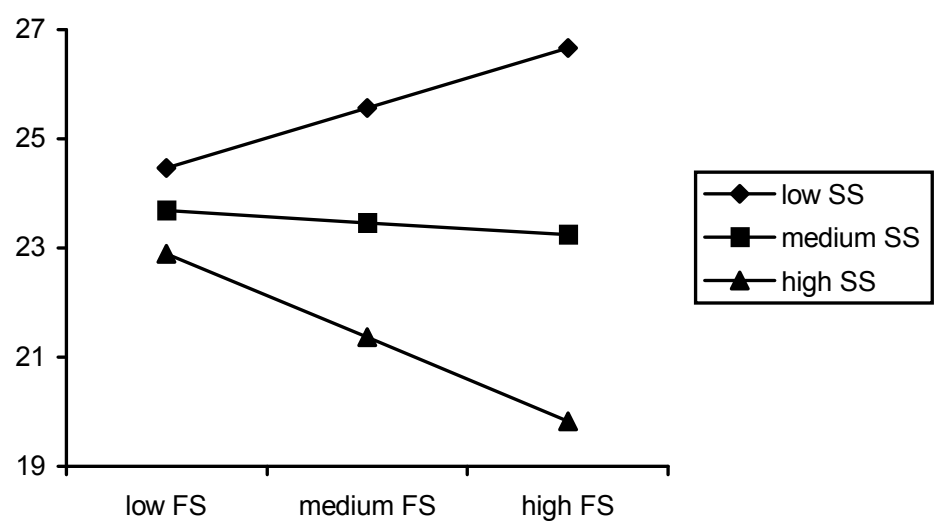

Figure 2: Interaction effect for Financial Strain and Social Support on Psychological Distress for Total sample

The results of the analysis with the young unemployed sample show that the variables account for a significant $50.20 \%$ of the variance in Psychological Distress, $F(15,126)=$ 8.46, $p<.001$. There were three significant individual predictors, which, in order of importance, were Neuroticism (contributing 16.08\%, $p<.001$ ), Financial Strain $(7.56 \%$, $p<.001)$, and Social Support $\mathrm{x}$ Financial Strain $(2.04 \%, p=.025)$. For the interaction effect, high Financial Strain was associated with increased Psychological Distress when Social Support was high and when Social Support was low, but not when Social Support was at a medium level (See Figure 3). For the middle-aged group, the variables account for a significant $44.30 \%$ of the variance in Psychological Distress, $F(15,109)=5.77, p<$ .001. Two significant individual predictors were identified. These were Neuroticism (contributing $10.11 \%, p<.001)$, and Financial Strain $(5.29 \%, p=.002)$. Lastly, for the Mature group, the variables accounted for $50.40 \%$ of Psychological Distress, $F(15,103)$ $=6.97, p<.001$. Only Neuroticism (contributing 29.27\%, $p<.001$ ) emerged as a significant individual predictor. Refer Table 6. 
Table 6

Summary data for Standard Multiple Regression Analysis for Variables Predicting Psychological Distress for Young, Middle-aged and Mature Groups

\begin{tabular}{|c|c|c|c|c|c|c|c|c|c|c|c|c|}
\hline \multirow[b]{2}{*}{ Variable } & \multicolumn{4}{|c|}{ Young Unemployed } & \multicolumn{4}{|c|}{ Middle-aged Unemployed } & \multicolumn{4}{|c|}{ Mature Unemployed } \\
\hline & $B$ & $S E B$ & $\beta$ & $\begin{array}{l}\text { Semi- } \\
\text { partial }\end{array}$ & $B$ & $S E B$ & $\beta$ & $\begin{array}{l}\text { Semi- } \\
\text { partial }\end{array}$ & $B$ & $S E B$ & $B$ & $\begin{array}{l}\text { Semi- } \\
\text { partial }\end{array}$ \\
\hline LAMB-TS & 0.02 & 0.05 & 0.02 & 0.02 & -0.04 & 0.06 & -0.05 & -0.05 & -0.07 & 0.05 & -0.12 & -0.11 \\
\hline LAMB-AC & -0.04 & 0.08 & -0.04 & -0.03 & 0.13 & 0.10 & 0.16 & 0.09 & -0.03 & 0.08 & -0.04 & -0.03 \\
\hline LAMB-SS & 0.01 & 0.05 & 0.02 & 0.01 & -0.06 & 0.06 & -0.09 & -0.07 & 0.04 & 0.06 & 0.07 & 0.05 \\
\hline LAMB-CP & 0.04 & 0.06 & 0.05 & 0.04 & 0.11 & 0.08 & 0.14 & 0.10 & 0.01 & 0.06 & 0.02 & 0.02 \\
\hline LAMB-ST & 0.09 & 0.08 & 0.11 & 0.07 & -0.01 & 0.09 & -0.02 & -0.01 & 0.12 & 0.07 & 0.18 & 0.12 \\
\hline LAMB-FS & 0.27 & 0.06 & $0.36^{* * *}$ & 0.28 & 0.22 & 0.07 & $0.32 * *$ & 0.23 & 0.11 & 0.06 & 0.17 & 0.12 \\
\hline LAMB-TS x LAMB-FS & -0.01 & 0.01 & -0.10 & -0.09 & 0.00 & 0.01 & 0.00 & 0.00 & 0.00 & 0.00 & 0.08 & 0.08 \\
\hline LAMB-AC x LAMB-FS & -0.00 & 0.01 & -0.03 & -0.03 & -0.01 & 0.01 & -0.08 & -0.05 & 0.01 & 0.01 & 0.20 & 0.10 \\
\hline LAMB-SS x LAMB-FS & 0.01 & 0.01 & $0.21 *$ & 0.14 & 0.00 & 0.01 & 0.07 & 0.06 & 0.00 & 0.01 & 0.00 & 0.00 \\
\hline LAMB-CP x LAMB-FS & -0.00 & 0.01 & -0.02 & -0.02 & 0.01 & 0.01 & 0.15 & 0.13 & -0.00 & 0.00 & -0.04 & -0.03 \\
\hline LAMB-ST x LAMB-FS & 0.00 & 0.01 & 0.04 & 0.02 & 0.00 & 0.01 & 0.05 & 0.03 & -0.01 & 0.01 & -0.12 & -0.07 \\
\hline EPQ-R & -1.04 & 0.16 & $-0.48 * * *$ & -0.40 & -0.83 & 0.19 & $-0.38 * * *$ & -0.32 & -1.36 & 0.17 & $-0.60 * * *$ & -0.54 \\
\hline Gender & 0.22 & 1.02 & 0.02 & 0.01 & -0.17 & 1.18 & -0.01 & -0.01 & 0.49 & 1.04 & 0.04 & 0.03 \\
\hline Age & 0.27 & 0.27 & 0.07 & 0.06 & -0.16 & 0.20 & -0.06 & -0.06 & -0.05 & 0.08 & -0.04 & -0.04 \\
\hline Length of Unemployment & -1.34 & 0.68 & -0.14 & -0.12 & -0.66 & 0.79 & -0.07 & -0.06 & 0.34 & 0.67 & 0.04 & 0.04 \\
\hline
\end{tabular}

Note 1: $\quad$ See Tables 1 and 5 for legend.

Note 2: $\quad$ For Young unemployed, $R^{2}=0.50$, Adjusted $R^{2}=0.44$, for Middle-aged unemployed, $R^{2}=0.44$, Adjusted $R^{2}=0.37$, for Mature unemployed, $R^{2}=$ 0.50 , Adjusted $R^{2}=0.43$

Note 3: $\quad *=p<.05 ; * *=p<.01 ; * * *=p<.001$ 


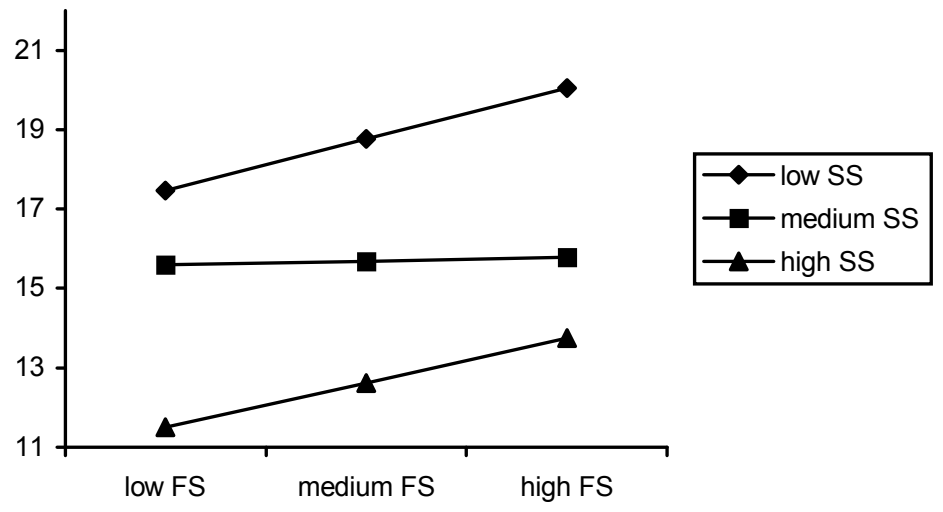

Figure 3: Interaction effect for Financial Strain and Social Support on Psychological Distress for Young sample

\section{Discussion}

No gender effects were found on any of the variables examined in the study. On the whole, males and females were equally distressed by their employment situation, which implies that females cannot be assumed to be less negatively affected than males, as has been the case by some researchers in the past. Males and females also reported similar access to the latent and manifest benefits of employment. Unemployed males and females did not differ on their levels of access to the latent or manifest benefits. The one age by gender interaction effect that was identified showed that middle-aged women and mature males reported significantly less activity than the other groups, although this was not reflected in meaningful associations with well-being. While maintaining regular activity may be important for all unemployed people, the results here suggest that middle-aged females and mature males are especially disadvantaged, and may benefit from interventions that encourage this. 
In relation to age main effects, the means for psychological distress showed a monotonic increase from young, middle-aged to mature, with the young unemployed recording less distress than the middle-aged and mature unemployed. This provides evidence for differential well-being effects between unemployed young people and unemployed adults, and not for a curvilinear relationship, which is consistent with Rowley and Feather's (1987) findings. One explanation for this might be the sample selection. Excluding the older $(>55$ years) and younger $(<18)$ unemployed (that is, those seeing themselves respectively as early retired or still dependent on their parents), would operate against identifying a non-linear relationship. It is likely that when adults are "truly" unemployed (and not identifying as being, for example, early retired) there are no psychological distress differences that are age based. One possible confounding issue here is Length of Unemployment, as the young unemployed were unemployed, on average, for shorter periods than the other two groups. Even though Length of Unemployment did not produce significant effects when controlled for in the analyses, because of the difficulty associated with measuring this variable, it cannot be ruled out as an explanation, and needs to be further investigated.

There were three main age effects identified for access to the latent benefits of employment. The young unemployed reported more social support (than the mature group), less concern about the negative status associated with unemployment (than the middle-aged and mature), and less time structure (than the middle-aged group), while there were no differences between the middle-aged and mature groups. This is an important result, as it indicates that there are differences in responses to at least some of Jahoda's latent benefits of employment. Other authors have suggested that when 
unemployed, young people may have more time to socialize (Roberts, 1983), while older unemployed are more likely to reduce their social activities, instead watching more television and engaging in more domestic duties (Warr, 1984). For the importance of social roles and identity, Creed and Bartrum (2003) have shown that unemployed people who identify themselves as the primary bread-winner in their household respond to unemployment differently than those who do not have this primary responsibility. It is likely that there were fewer primary bread-winners in the young group. This could mean that the young people were more able to identify with other legitimate roles than being unemployed, and might account for the age differences on this variable. In relation to loss of time structure, Jahoda (1982) argued that this was the most important negative consequence of unemployment. Yet, while the young unemployed reported poorer time structure than the other groups, this was not correlated at all with distress in this group.

When the predictors of psychological distress are examined, the personality variable of Neuroticism emerged as the most important individual variable for the Total sample, and for the young, middle-aged and mature groups, accounting for $18 \%, 17 \%$, $11 \%$ and $30 \%$ respectively. This is consistent with the results of other studies which show that neuroticism is an important predictor of well-being (Creed et al., 1996), although the evidence here is that it is far more important for predicting well-being in older individuals than younger. Neuroticism was the only significant individual predictor in the mature group, indicating that the latent and manifest benefits play a minor role here compared to temperament. The next most important individual predictor was Financial Strain, accounting for $4 \%$ in the Total sample, $7 \%$ in the young, $5 \%$ in the middle-aged and a non-significant $2 \%$ in the mature group. This is not consistent with the curvilinear age by 
psychological distress hypothesis, which suggests that middle-aged unemployed are more distressed by unemployment primarily because of financial commitments, whereas the younger and older individuals are less distressed as they have less financial strain. In this sample, financial strain was a more important predictor of distress in the younger rather than the other two groups.

The other significant individual predictor was the interaction between Social Support and Financial Strain. This emerged in the Total sample as well as in the young group. This is also an important finding as it demonstrates that the loss of the manifest benefits of employment may affect well-being directly, but can also affect it in combination with the latent benefits. In this study, elevated Financial Strain was associated with increased Psychological Distress when Social Support was low (for the Total sample), and associated with increased Psychological Distress when Social Support was high and when Social Support was low, but not when Social Support was at a medium level (for the young group). In this case, Social Support may then operate as a moderator between Financial Strain and well-being, suggesting, for example, that when Financial Strain is high, the unemployed may not access social support or may not be able to participate in social events. Despite calls in the literature, this is the first time an interaction between the latent and manifest benefits has been tested, and models developed to account for a decline in well-being in the unemployed need to consider Financial Strain in this light. This finding also highlights the importance of Financial Strain in predicting well-being in the unemployed, and lends credence to Fryer's (1995) assertions that poverty, rather than the loss of the latent benefits of employment, is the most important variable associated with poor well-being in the unemployed. 
This study has demonstrated differences in the latent and manifest benefits across different age groups. An important issue that still needs to be resolved is whether, and under what conditions, well-being and access to the latent and manifest benefits of employment change and inter-relate over time as unemployment continues. Neither Jahoda's nor Fryer's models address these process questions. Stage (e.g., Borgen \& Amundson, 1987) and process (e.g., Latack, Kinicki \& Prussia, 1995) models have been proposed to account for the changes in well-being that has been observed as unemployment continues, although these models have not been widely tested empirically. An example of one variable that has been examined is that of Financial Strain. Waters and Moore (2001) hypothesised that unemployed adults curtail spending on discretionary items in the early stages of unemployment, and curtail spending on necessities as unemployment persists, and demonstrated a relationship between Financial Strain, measured in this way, and well-being. The changing nature of the latent, as well as the manifest, benefits and their relationship with well-being, age and gender need to be examined in this context. 


\section{References}

Australian Bureau of Statistics. (2001). Labour Force Australia (6202.0). Canberra.

Australian Bureau of Statistics. (2003). Labour Force (UN) Unemployed - AustraliaMonthly. Time Series Spreadsheet 6291.0.40.001. Canberra.

Borgen, W. A., \& Amundson, N. E. (1987). The dynamics of unemployment. Journal of Counselling and Development, 66, 180-184.

Broomhall, H. S., \& Winefield, A. H. (1990). A comparison of the affective wellbeing of young and middle-aged unemployed men matched for length of unemployment. British Journal of Medical Psychology, 63, 43-52.

Creed, P. A. (1999). Predisposing factors and consequences of occupational status for long-term unemployed youth: A longitudinal study. Journal of Adolescence, 22, 81-93.

Creed, P. A., \& Bartrum, D. (2003). Testing the latent and manifest benefits of employment as demands in the control-demand model with an unemployed sample. Submitted for review.

Creed, P. A., \& Machin, M. A. (2002). The relationship between mental health and access to the latent benefits of employment for unemployed and underemployed individuals. Psychological Reports, 90, 1208-1210.

Creed, P. A., \& Macintyre, S. R. (2001). The relative effects of deprivation of the latent and manifest benefits of employment on the wellbeing of unemployed people. Journal of Occupational Health Psychology, 6(4), 324-331.

Creed, P. A., \& Muller, J. (2003). Predicting psychological distress across occupational settings: Shame or deprivation. Submitted for review. 
Creed, P. A., Machin, M. A., \& Hicks, R. (1996). Neuroticism and mental health outcomes for long-term unemployed youth attending occupational skills training programs. Personality and Individual Differences, 21(4), 537-544.

Diener, E., Suh, E., Lucas, R., \& Smith, H. (1999). Subjective well-being: Three decades of progress. Psychological Bulletin, 125(2), 276-302.

Deci, E. L., \& Ryan, M. (1985). The General Causality Orientation Scale: Selfdetermination in personality. Journal of Research on Personality, 19, 109-134.

Eysenck, H. J., \& Eysenck, S. B. G. (1996). Manual of the Eysenck Personality Scales (EPS-Adult). London: Hoder \& Stoughton Educational.

Feather, N. T., \& O'Brien, G. E. (1986). A longitudinal study of the effects of employment and unemployment on school leavers. Journal of Occupational Psychology, 59, 121-144.

Frydenberg, E., \& Lewis, E. (1991). Adolescent coping: The different ways in which boys and girls cope. Journal of Adolescence, 14(2), 119-133.

Fryer, D. M. (1995). Benefit agency? Labour market disadvantage, deprivation and mental health. The Psychologist, June, 265-272.

Goldberg, D. P. (1972). The detection of psychiatric illness by questionnaire. London: Oxford University Press.

Hair, J. F., Anderson, R. E., Tatham, R. L., \& Black, W. C. (1998). Multivariate Data Analysis (5 $5^{\text {th }}$ Ed.). New Jersey: Prentice-Hall.

Hammarström, A., \& Janlert, U. (1997). Nervous and depressive symptoms in a longitudinal study of youth unemployment - selection or exposure? Journal of Adolescence, 20, 293-305. 
Haworth, J. T. (1997). Work, leisure and well-being. London: Routledge.

Jackson, T. (1999). Differences in psychosocial experiences of employed, unemployed, and student samples of young adults. Journal of Psychology, 133(1), 49-60.

Jahoda, M. (1982). Employment and Unemployment: A Social-psychological Analysis. London: Cambridge University Press.

Kasl, S. V., \& Cobb, S. (1979). Some mental health consequences of plant closing and job loss. In L. A. Ferman \& J. P. Gordus (Eds.). Mental health and the economy. Upjohn: Kalamazoo.

Kaufman, D., \& Fetters, M. L. (1980). Work motivation and job values among professional men and women: A new accounting. Journal of Vocational Behaviour, $17(3), 251-262$.

Kulik, L. (2001). Impact of length of unemployment and age on jobless men and women: A comparative analysis. Journal of Employment Counseling, 38(1), 15-27.

Lahelma, E. (1992). Unemployment and mental well-being: Elaboration of the relationship. International Journal of Health sciences, 22, 261-274.

Latack, J. C., Kinicki, A. J., \& Prussia, G. E. (1995). An integrative process model of coping with job loss. Academy of Management Review, 20(2), 311-342.

Mi'ari, M. (1996). Work satisfaction and gender. International Review of Modern Sociology, 26(1), 67-69.

Muller, J., Creed, P. A., Waters, L., \& Machin, M. A. (2000). The development and validation of a scale to measure the manifest and latent functions of employment. Paper presented at $27^{\text {th }}$ International Congress of Psychology, 23-28 July, Stockholm, Sweden. 
Muller, J., Hicks, R., \& Winocur, S. (1993). The effects of employment and unemployment on psychological well-being in Australian clerical workers: Gender differences. Australian Journal of Psychology. 45(3): 103-108.

Murphy, G. C., \& Athanasou, J. (1999). The effect of unemployment on mental health. Journal of Occupational and Organizational Psychology, 72, 83-99.

Roberts, K. (1983). Youth and Leisure. London: Allen \& Unwin.

Rowley, K. M., \& Feather, N. T. (1987). The impact of unemployment in relation to age and length of unemployment. Journal of Occupational Psychology, 60(4), 323-332.

Shamir, B. (1986). Self-esteem and the psychological impact of unemployment in relation to age and length of unemployment. Social Psychology Quarterly, 49, 61-72.

Tabachnik, B. G., \& Fidell, L. S. (1996). Using Multivariate Statistics. New York: HarperCollins College Publishers.

Underlid, K. (1996). Activity during unemployment and mental health. Scandinavian Journal of Psychology, 37(3), 269-281.

Wanberg, C. R., Griffiths, R. F., \& Gavin, M. R. (1997). Time structure and unemployment: A longitudinal investigation. Journal of Occupational and Organizational Psychology, 70, 75-95.

Warr, P. B. (1984). Reported behaviour changes after job loss. British Journal of Social Psychology, 23, 271-275.

Warr, P. B. (1987). Work, unemployment and mental health. Oxford: Oxford University Press.

Warr, P. B., \& Jackson, P. R. (1984). Men without jobs: Some correlates of age and length of unemployment. Journal of Occupational Psychology, 57, 77-85. 
Warr, P. B., \& Jackson, P. R. (1985). Factors influencing the psychological impact of prolonged unemployment and of re-employment. Psychological Medicine, 15, 795-807.

Warr, P. B., \& Jackson, P. R. (1987). Adapting to the unemployed role: A longitudinal investigation. Social Science and Medicine, 25, 1219-1224.

Warr, P. B., Jackson, P., \& Banks, M. (1988). Unemployment and mental health: Some British studies. Journal of Social Issues, 44, 47-67.

Warr, P. B., \& Parry, G. (1982). Paid employment and women's psychological well being. Psychological Bulletin, 91, 498-516.

Warr, P. B., \& Payne, R. L. (1983). Social class and reported changes in behaviour after job loss. Journal of Applied Social Psychology, 13, 206-222.

Waters, L. E., \& Moore, K. A. (2001). Coping with economic deprivation during unemployment. Journal of Economic Psychology, 22, 461-482.

Waters, L. E., \& Moore, K. A. (2002). Reducing latent deprivation during unemployment: The role of meaningful leisure activity. Journal of Occupational and Organizational Psychology, 75, 15-32.

Winefield, A. H. (1995). Unemployment: Its psychological costs. In C. L. Cooper \& I. T. Robertson (Eds.). International Review of Industrial and Organizational Psychology. Chichester: Wiley.

Winefield, A. H., \& Tiggemann, M. (1985). Psychological correlates of employment and unemployment: Effects, predisposing factors and sex differences. Journal of Occupational Psychology, 58, 229-242.

Winefield, A. H., Tiggemann, M., Winefield, H. R., \& Goldney, R. D. (1993). Growing up with unemployment. London: Routledge. 